\title{
Human dental pulp stem cells can differentiate into Schwann cells and promote and guide neurite outgrowth in an aligned tissue-engineered collagen construct in vitro
}

\author{
Wendy Martens, ${ }^{*, 1,2}$ Kathleen Sanen, ${ }^{\dagger, 1}$ Melanie Georgiou, ${ }^{\ddagger}, \S$ Tom Struys, ${ }^{*}$ \\ Annelies Bronckaers, ${ }^{*}$ Marcel Ameloot, ${ }^{\dagger}$ James Phillips, ${ }^{\ddagger}, \|$ and Ivo Lambrichts* \\ *Department of Functional Morphology and ${ }^{\dagger}$ Department of Biophysics, Biomedical Research \\ Institute (BIOMED), Hasselt University, Diepenbeek, Belgium; ${ }^{\dagger}$ Department of Life, Health, and \\ Chemical Sciences, The Open University, Milton Keynes, UK; ${ }^{{ }^{\S}}$ Department of Biochemical \\ Engineering and ${ }^{\|}$Department of Biomaterials and Tissue Engineering, Eastman Dental Institute, \\ University College London, London, UK
}

\begin{abstract}
In the present study, we evaluated the differentiation potential of human dental pulp stem cells (hDPSCs) toward Schwann cells, together with their functional capacity with regard to myelination and support of neurite outgrowth in vitro. Successful Schwann cell differentiation was confirmed at the morphological and ultrastructural level by transmission electron microscopy. Furthermore, compared to undifferentiated hDPSCs, immunocytochemistry and ELISA tests revealed increased glial marker expression and neurotrophic factor secretion of differentiated hDPSCs (dhDPSCs), which promoted survival and neurite outgrowth in 2-dimensional dorsal root ganglia cultures. In addition, neurites were myelinated by d-hDPSCs in a 3-dimensional collagen type I hydrogel neural tissue construct. This engineered construct contained aligned columns of d-hDPSCs that supported and guided neurite outgrowth. Taken together, these findings provide the first evidence that hDPSCs are able to undergo Schwann cell differentiation and support neural outgrowth in vitro, proposing them to be good candidates for cell-based therapies as treatment for peripheral nerve injury.-Martens, W., Sanen, K., Georgiou, M., Struys, T., Bronckaers, A., Ameloot, M., Phillips, J.,
\end{abstract}

Abbreviations: 2D, 2-dimensional; 3D, 3-dimensional; $\alpha \mathrm{MEM}$, minimal essential medium, $\alpha$ modification; BDNF, brain-derived neurotrophic factor; b-FGF, basic fibroblast growth factor; BME, $\beta$-mercaptoethanol; b-NGF, nerve growth factor b; CNTF, ciliary neurotrophic factor; DAPI, 4',6-diamidino-2-phenylindole; dhDPSC, differentiated human dental pulp stem cell; DRG, dorsal root ganglion; ELISA, enzyme-linked immunosorbent assay; EngNT, engineered neural tissue; FBS, fetal bovine serum; GDNF, glia-derived neurotrophic factor; GFAP, glial fibrillary acidic protein; hDPSC, human dental pulp stem cell; MSC, mesenchymal stem cell; NF, neurotrophic factor; NRG, heregulin- $\beta-1$; NT-3, neurotrophin 3 ; PDGFaa, platelet-derived growth factor AA; PFA, paraformaldehyde; PNI, peripheral nerve injury; RA, all trans-retinoic acid; TEM, transmission electron microscopy; VEGF, vascular endothelial growth factor
Lambrichts, I. Human dental pulp stem cells can differentiate into Schwann cells and promote and guide neurite outgrowth in an aligned tissue-engineered collagen construct in vitro. FASEB J. 28, 1634-1643 (2014). www.fasebj.org

Key Words: neural regeneration $\cdot$ nerve repair $\cdot$ glial cell $\cdot$ myelination $\cdot$ cellular hydrogel

A VARIETY OF TRAUMAS AND diseases can cause peripheral nerve injury (PNI), which often results in chronic pain and disability (1). Endogenous repair is known to initiate after injury and is strongly dependent on the contribution of Schwann cells, as the regenerative capacity of peripheral nerves is reduced in their absence (2). Schwann cells not only reconstitute myelin, which is essential for fast neural action potential propagation, but also provide physical guidance (bands of Büngner) and trophic support for axonal regeneration. Regeneration following nerve transection is limited by the distance between the nerve stumps, and bridging strategies are required where direct end-to-end repair is not feasible. Bridging strategies include the use of tubes and decellularized nerve tissue, and, for longer gaps $(>3 \mathrm{~mm})$, the nerve autograft is currently regarded as the gold standard (1). While autografts provide Schwann cells and appropriate architecture for regeneration, there are problems with availability

\footnotetext{
${ }^{1}$ These authors contributed equally to this work.

${ }^{2}$ Correspondence: Hasselt University, Campus Diepenbeek, Biomedical Research Institute, Lab of Histology, Agoralaan, Bldg. C, Office C011, 3590 Diepenbeek, Belgium. E-mail: wendy.martens@uhasselt.be

This is an Open Access article distributed under the terms of the Creative Commons Attribution 3.0 Unported (CC BY 3.0) (http://creativecommons.org/licenses/by/3.0/deed. en_US) which permits unrestricted use, distribution, and reproduction in any medium, provided the original work is properly cited.

doi: $10.1096 /$ fj.13-243980
} 
and donor site morbidity, and overall clinical outcomes show limited success $(1,3)$.

A wide range of biomaterial and tissue engineering approaches have been used to generate potential alternatives that recreate beneficial aligned cellular features of the autograft (4-6). In particular, hydrogels made from natural proteins have gained significant interest due to their functional extracellular matrix properties, inherent biocompatibility, and suitability as carriers for different cell types $(7,8)$; however, there are limitations associated with the generation and maintenance of guidance architecture in hydrogels (9). A technique was recently developed to align and stabilize Schwann cells and collagen fibrils in a collagen type I hydrogel, thereby generating an aligned tissue-like cellular biomaterial for neural tissue engineering (10). For this approach to be clinically useful, a suitable source of Schwann cells is required for the engineered neural tissue (EngNT) construct. The use of autologous Schwann cells for PNI is restricted because their isolation requires resection of another peripheral nerve, and they are known to expand slowly when cultured in vitro, thereby leading to the need for alternative cell sources $(11,12)$.

Adult stem cells, such as mesenchymal stem cells (MSCs), are promising candidates to treat PNI. MSCs can be isolated from a wide range of tissues and have been shown to secrete neurotrophic factors (NFs) capable of inducing axonal outgrowth, and they can differentiate into Schwann-like cells or neurons (13, 14). A promising alternative cell source is human dental pulp stem cells (hDPSCs; ref. 15). These are ectoderm-derived stem cells, originating from migrating neural crest cells and possessing MSC properties $(16-19)$. The resulting stem cell population can be easily isolated from discarded wisdom teeth without the need for invasive tissue harvest associated with other sources of MSCs. Furthermore, their stem cell properties are retained after cryopreservation, providing the opportunity to establish a stem cell bank $(15,20)$. In addition to their ability to differentiate into cells of mesodermal lineages, hDPSCs have the potential to differentiate along the neural lineage. Even in an undifferentiated state, hDPSCs already express neural markers like S100, $\beta$-III-tubulin, and nerve growth factor receptor p75 and are able to produce and secrete a range of NFs, ciliary neurotrophic factor (CNTF), vascular endothelial growth factor (VEGF), brain-derived neurotrophic factor (BDNF), glia-derived neurotrophic factor (GDNF), and nerve growth factor $b$ (b-NGF), thereby enhancing and guiding axonal outgrowth (21-25). Although several groups have already reported in vitro neuronal differentiation of hDPSCs (26-28), the differentiation of hDPSCs toward Schwann cells has not been reported to date.

Here we established a protocol for glial differentiation of hDPSCs in vitro and assessed the functional capacity of differentiated hDPSCs (d-hDPSCs) with regard to myelination and support of neurite growth. Our findings provide the first evidence that hDPSCs are able to undergo differentiation toward Schwann-like cells that support neural outgrowth in vitro, revealing them to be good candidates for cell-based therapies to treat PNI.

\section{MATERIALS AND METHODS}

\section{Materials and products}

All products were purchased from Sigma-Aldrich (Bornem, Belgium) unless stated otherwise.

\section{Isolation and differentiation of hDPSCs into Schwann-like cells}

Human third molars were collected with written informed consent from donors (15-20 yr of age) undergoing tooth extraction for orthodontic or therapeutic reasons at Ziekenhuis Oost-Limburg (Genk, Belgium). When donors were underaged, written informed consent was obtained via their legal guardians. This study was approved by the medical ethical committee of Hasselt University. hDPSCs were isolated from dental pulp tissue via the explant method previously described (29). hDPSCs were maintained in minimal essential medium, $\alpha$ modification $(\alpha \mathrm{MEM})$ supplemented with $10 \%$ fetal bovine serum (FBS, Biochrom AG, Berlin, Germany), 2 mM L-glutamine, $100 \mathrm{U} / \mathrm{ml}$ penicillin, and $100 \mu \mathrm{g} / \mathrm{ml}$ streptomycin. When $80-90 \%$ confluency was reached, cells were routinely subcultured.

At passage 2-3, Schwann cell differentiation was induced by changing the medium to standard culture medium without FBS containing $1 \mathrm{mM} \beta$-mercaptoethanol (BME) for $24 \mathrm{~h}$. Subsequently cells were incubated in standard culture medium supplemented with $35 \mathrm{ng} / \mathrm{ml}$ all trans-retinoic acid (RA). After $72 \mathrm{~h}$, medium was changed to standard culture medium supplemented with $5 \mu \mathrm{M}$ forskolin, $10 \mathrm{ng} / \mathrm{ml}$ basic fibroblast growth factor (b-FGF), $5 \mathrm{ng} / \mathrm{ml}$ platelet-derived growth factor AA (PDGFaa), and $200 \mathrm{ng} / \mathrm{ml}$ heregulin- $\beta-1$ (NRG) (Immunotools, Friesoythe, Germany). The cells were cultured in this supplemented medium for $2 \mathrm{wk}$ with medium changes every 2-3 d (30). hDPSCs differentiated toward Schwann-like cells are henceforth referred to as d-hDPSCs. Both hDPSCs and d-hDPSCs were grown at $37^{\circ} \mathrm{C}$ in a humidified atmosphere with $5 \% \mathrm{CO}_{2}$

\section{Collection of conditioned medium}

hDPSCs were seeded at a density of 20,000 cells $/ \mathrm{cm}^{2}$ in standard hDPSC culture medium. After $24 \mathrm{~h}$, hDPSCs were rinsed with PBS and incubated with standard culture medium supplemented with $0.1 \%$ FBS instead of $10 \%$ FBS. After $48 \mathrm{~h}$ of incubation, the medium was collected and stored at $-80^{\circ} \mathrm{C}$. Furthermore, conditioned medium from d- hDPSCs was collected as described above and stored at $-80^{\circ} \mathrm{C}$.

\section{Isolation of primary Schwann cells}

Primary Schwann cells were isolated from postnatal d 17 Sprague-Dawley rats as described previously (31) with minor modifications. Briefly, sciatic nerves were dissected out and stripped free of epineurium. Following enzymatic treatment with $0.25 \%$ collagenase and $0.25 \%$ trypsin-EDTA, the nerve segments were mechanically dissociated. Cells from 2 nerve segments ( 1 animal) were seeded in a T25 flask precoated with $10 \mu \mathrm{g} / \mathrm{ml}$ poly-L-lysine. Further purification of the culture was performed as previously described (31).

\section{Immunocytochemistry}

An immunocytochemical analysis was performed on hDPSCs, d-hDPSCs and primary Schwann cells with antibodies against glial fibrillary acidic protein (GFAP; 1:400; Leica Microsystems/NovoCastra, Diegem, Belgium), p75 (1:50, Dakocytomation, Glostrup, Denmark), laminin (1:1000, Abcam, Cam- 
bridge, UK), CD104 (1:100, Abcam), and nestin (1:500, Millipore, MA, USA) to determine the immunophenotype after differentiation. Cells were fixed with $4 \%$ paraformaldehyde (PFA) at $4^{\circ} \mathrm{C}$ for $20 \mathrm{~min}$ and washed with PBS. In case of intracellular targets, cells were permeabilized with Triton-X $0.05 \%$ for $30 \mathrm{~min}$ at $4^{\circ} \mathrm{C}$. To block nonspecific binding sites, cells were incubated with $10 \%$ normal donkey serum at room temperature for $20 \mathrm{~min}$. After washing with PBS, cells were incubated with primary antibody for $1 \mathrm{~h}$, followed by incubation with donkey anti-rabbit Alexa488 (1:500) or donkey anti-mouse Alexa555 (1:500) secondary antibodies for $30 \mathrm{~min}$ at room temperature. Slides were mounted using 4',6-diamidino-2-phenylindole (DAPI) with Prolong Gold Antifade (Molecular Probes, Merelbeke, Belgium). Fluorescence was visualized with a Nikon Eclipse 80i fluorescence microscope equipped with a Nikon DS-2MBWc digital camera (Nikon, Tokyo, Japan). Samples in which primary antibodies were omitted were used as a negative control.

\section{Ultrastructural analysis: transmission electron microscopy (TEM)}

Following fixation with $2 \%$ glutaraldehyde (Laborimpex, Brussels, Belgium) in $0.05 \mathrm{M}$ cacodylate buffer ( $\mathrm{pH} 7.3$; Aurion, Wageningen, the Netherlands) at $4^{\circ} \mathrm{C}$, the fixative was gently aspirated with a glass pipette, and the cells were postfixed in $2 \%$ osmium tetroxide (Aurion) for $1 \mathrm{~h}$. Subsequently, the cell-seeded coverslips were put through a dehydrating series of graded concentrations of acetone and embedded in araldite according to the popoff method (32). Ultrathin sections $(0.06 \mu \mathrm{m})$ were mounted on $0.7 \%$ formvarcoated copper grids (Aurion), contrasted with $0.5 \%$ uranyl acetate and a stabilized solution of lead citrate (both from Laurylab, Saint-Fons Cedex, France), and examined in a Philips EM 208 transmission electron microscope (Philips, Eindhoven, The Eindhoven) operated at $80 \mathrm{kV}$. The microscope was provided with a Morada Soft Imaging System (SIS; Olympus, Tokyo, Japan) camera to acquire high-resolution images of the evaluated samples. The images were processed digitally with iTEM-FEI software (Olympus SIS).

\section{Enzyme-linked immunosorbent assay (ELISA)}

ELISAs were performed on conditioned medium derived from hDPSCs and d-hDPSCs in order to determine the concentration of BDNF, GDNF, neurotrophin 3 (NT-3) and b-NGF (RayBiotech, Boechout, Belgium). Experiments were performed in triplicate and absorbance was measured at $450 \mathrm{~nm}$ by means of the FLUOstar Optima multifunctional microplate reader (BMG Labtech, Ortenberg, Germany). Conditioned medium from 9 different donors was used, and ELISA tests were performed according to the manufacturer's protocol.

\section{Neonatal dorsal root ganglion (DRG) neuron cell cultures: 2-dimensional (2D) experiments}

Experimental procedures involving neonatal animals were approved by the Hasselt University animal ethics advisory group. DRGs were harvested from 5-d-old Sprague-Dawley rat pups. Briefly, isolated DRG explants were dissociated with $0.025 \%$ collagenase at $37^{\circ} \mathrm{C}$ for $1 \mathrm{~h}$. Dissociated cells were seeded onto coverslips at a density of 25,000 cells $/ \mathrm{cm}^{2}$. Coverslips were precoated with poly-L-lysine $(10 \mu \mathrm{g} / \mathrm{ml})$ for 1 $\mathrm{h}$. At 1-2 $\mathrm{h}$ after cell plating, medium was changed to remove nonadhering cells. Neurons were cultured for $24 \mathrm{~h}$ in DMEM/F12 medium supplemented with Glutamax, 10\% FBS, $100 \mathrm{U} / \mathrm{ml}$ penicillin, and $100 \mu \mathrm{g} / \mathrm{ml}$ streptomycin.

\section{Survival assay}

Isolated neonatal DRG cultures were seeded in a 96-well plate at a density of 10,000 cells/well. The next day, cells were washed twice with PBS, and the medium was replaced with conditioned medium from hDPSCs or d-hDPSCs. $\alpha$ MEM with 10 or $0.1 \%$ FBS (henceforth DRG $0.1 \%$ ) was used as positive or negative control, respectively. After $48 \mathrm{~h}$, the medium was removed, and $500 \mu \mathrm{g} / \mathrm{ml}$ MTT was added to the wells. The MTT solution was removed after an incubation time of $4 \mathrm{~h}$ at $37^{\circ} \mathrm{C}$. A mixture of $0.01 \mathrm{M}$ glycine and DMSO was added to each well. The absorbance was measured at a wavelength of $540 \mathrm{~nm}$ with a Benchmark microplate reader (Bio-Rad Laboratories, Nazareth Eke, Belgium). Conditioned medium from cultures from $\geq 7$ different donors was used.

\section{Neurite regeneration assay}

Neonatal DRG cultures were incubated with conditioned medium from hDPSCs or d-hDPSCs to analyze the effect on neurite outgrowth. $\alpha$ MEM with $10 \%$ FBS or DRG $0.1 \%$ was used as positive or negative control, respectively. After $48 \mathrm{~h}$, cells were fixed in 4\% PFA and immunostained using anti- $\beta$ III-tubulin. Four independent experiments were carried out, and neurite outgrowth was assessed by measuring the length of the longest neurite of individual cells.

\section{Adult DRG cell cultures: 3-dimensional (3D) experiments}

Experimental procedures involving adult animals were conducted in accordance with the UK Animals (Scientific Procedures) Act (1986) and approved by the Open University animal ethics advisory group. Dissociated DRG cultures were prepared from adult (200-300 g) Sprague-Dawley rats that were culled using $\mathrm{CO}_{2}$ asphyxiation. Briefly, spines were removed, and DRG explants were collected in DMEM with $10 \%$ FBS and $100 \mathrm{U} / \mathrm{ml}$ penicillin and $100 \mu \mathrm{g} / \mathrm{ml}$ streptomycin. After removal of the connective tissue and nerve roots, DRGs were placed into a collagenase solution $(0.125 \%)$ at $37^{\circ} \mathrm{C}$. After $90 \mathrm{~min}$ of incubation, collagenase was removed, and explants were triturated in DMEM with $10 \%$ FBS until a homogenous cell suspension was obtained. Next, cells were transferred to culture flasks containing DMEM with $10 \% \mathrm{FBS}, 100 \mathrm{U} / \mathrm{ml}$ penicillin, $100 \mu \mathrm{g} / \mathrm{ml}$ streptomycin, and $10 \mu \mathrm{M}$ cytosine arabinoside (Ara-C) for $24 \mathrm{~h}$ to deplete the non-neuronal cells.

\section{Myelination in hydrogel}

d-hDPSC-seeded collagen gels were tethered within rectangular stainless steel molds according to methods described previously (33-35). Gels were prepared using 10\% cell suspension (a mixture of 250,000 d-hDPSCs and 5 dissociated DRG explants per milliliter of gel) mixed with $10 \%$ MEM and $80 \%$ type I rat tail collagen $(5 \mathrm{mg} / \mathrm{ml}$ in $0.6 \%$ acetic acid; First Link, Wolverhampton, UK) following neutralization using sodium hydroxide. This mixture $(1 \mathrm{ml})$ was added to each mold at $4^{\circ} \mathrm{C}$ and integrated with tethering mesh at opposite ends before setting at $37^{\circ} \mathrm{C}$ for $10 \mathrm{~min}$. Tethered gels were immersed in medium, and after $2 \mathrm{wk}$, the contracted hydrogels were fixed overnight with $4 \%$ PFA at $4^{\circ} \mathrm{C}$. The higher collagen concentration (compared to tethered gels used in EngNT assembly) delayed the process of hydrogel contraction and cell alignment, thereby allowing long-term incubation of the uncompressed cellular hydrogel in the mold.

\section{TEM of cellular hydrogels}

Cellular hydrogels were fixed with 4\% PFA and processed for TEM as described above, with the ultrathin sections sliced perpendicular 
to the longitudinal axis of the hydrogel in this case. The total numbers of d-hDPSCs and neurites were manually counted in each ultrathin section ( 3 sections/gel, $n=5$ gels). A distance of $<40 \mathrm{~nm}$ between a neurite and a d-hDPSC was considered to be a contact between cell types. Data were normalized to number per square millimeter of hydrogel section.

\section{Generation of EngNT using d-hDPSCs}

A cell-seeded collagen gel was prepared as described above, with some modifications. d-hDPSCs were suspended in a collagen type I solution of $2 \mathrm{mg} / \mathrm{ml}$ (First Link) to give a final density of $10^{6}$ cells $/ \mathrm{ml}$ gel mixture. Tethered gels were immersed in medium for $4-6 \mathrm{~h}$ to allow alignment to develop. Aligned cellular gels were stabilized by plastic compression: Aligned tethered gels were separated from the tethering mesh using a scalpel, then immediately compressed by loading the gel with $120 \mathrm{~g}$ for $1 \mathrm{~min}$, while fluid was removed into a porous paper pad underneath. The resulting sheets of EngNT were transferred to 24-well plates for in vitro neurite growth experiments.

\section{Seeding of dissociated DRG neurons on top of EngNT}

Adult DRG neurons (20 dissociated DRG explants) were seeded onto the surface of each EngNT sheet and allowed to settle for $30 \mathrm{~min}$, and then constructs were immersed in medium at $37^{\circ} \mathrm{C}$ in a humidified incubator with $5 \% \mathrm{CO}_{2}$. After $3 \mathrm{~d}$, the EngNT-neuron cocultures were washed briefly in PBS and fixed in $4 \%$ PFA at $4^{\circ} \mathrm{C}$ for $24 \mathrm{~h}$, followed by immunofluorescence staining as described previously for collagen gels $(36,37)$, to detect $\beta$-III-tubulin positive neurons and S100-positive Schwann cells.

\section{Analysis of angle of deviation}

Confocal microscopy (Leica SP5) was used in the assessment of d-hDPSC alignment in EngNT, and d-hDPSC and neurite alignment and growth in the EngNT-neuron cocultures. Four equivalent fields were analyzed per gel using a predetermined sampling protocol. The total area sampled per gel was 0.49 $\mathrm{mm}^{2}$. Images were captured using a $\times 40$ oil immersion lens, and $z$-stacks were $20 \mu \mathrm{m}$, with a step size of $1 \mu \mathrm{m}$. Image analysis was conducted using Volocity software (PerkinElmer, Waltham, MA, USA) running automated 3D image analysis protocols to measure the angle of Schwann cell alignment and neurite alignment in each field. To evaluate the directional growth of neurites on EngNT containing d-hDPSCs, angles of neurites deviating from the mean d-hDPSC angle in each field were measured.

\section{Statistical analysis}

Statistical analysis was performed using GraphPad Prism 5 software (GraphPad, San Diego, CA, USA). Data from the survival assay and neurite outgrowth were first controlled for normality by means of a D'Agostino-Pearson omnibus normality test, followed by comparison of control and experimental groups by means of a Kruskal-Wallis test while applying a Dunn's multiple comparison post hoc test. Data from ELISA tests were submitted to a D'Agostino-Pearson omnibus normality test, followed by an unpaired $t$ test. Data from the proliferation assays were compared by means of a 2-way ANOVA followed by Bonferroni's multiple comparison test. Values of $P \leq 0.05$ were considered statistically significant. All data are expressed as means \pm SEM.

\section{RESULTS}

\section{Morphology and immunophenotype of d-hDPSCs in vitro}

Schwann cell differentiation was induced in hDPSCs at passage 2-3. In vitro, undifferentiated hDPSCs displayed a flattened fibroblast-like morphology (Fig. 1A). After $24 \mathrm{~h}$ in differentiation medium containing $1 \mathrm{mM}$ BME, cells adopted an elongated shape. Following the induction protocol, cells acquired a bipolar cell morphology resembling primary rat Schwann cells in culture (Fig. $1 B, C$ ).

To evaluate the expression of glial markers, immunocytochemical staining was performed with antibodies against laminin, p75, GFAP, CD104, and nestin in hDPSCs, d-hDPSCs, and Schwann cells. Both Schwann cells and d-hDPSCs showed a positive immune reaction for laminin, p75, GFAP, and CD104 (Fig. 1D-O). Furthermore, expression of the early neural marker nestin decreased in differentiated cell cultures compared to hDPSCs and was not detected in Schwann cells (Fig. $1 P-R)$.

At the ultrastructural level, hDPSCs and d-hDPSCs displayed large euchromatic nuclei with prominent nucleoli. Within the cytoplasm of hDPSCs, a perinuclear zone was observed containing organelles such as mitochondria, rough endoplasmatic reticulum cisternae, and some Golgi apparatus (Fig. 2A-C). In cultures of d-hDPSCs, however, organelles were spread throughout the cytoplasm, and cell-cell contacts were often visible between neighboring cells (Fig. 2D, E; oval).

\section{Secretion of neurotrophic factors by hDPSCs and d-hDPSCs}

The concentration of GDNF, BDNF, NT-3, and b-NGF, secreted in the conditioned medium of hDPSCs and d-hDPSCs, was determined by means of ELISA (Fig. 3A) . The levels of BDNF, b-NGF, NT-3, and GDNF were significantly increased after differentiation by 1.60-, 3.68-, 2.02-, and 8.27-fold, respectively.

DRG cultures were incubated with conditioned medium of hDPSCs or d-hDPSCs for $48 \mathrm{~h}$. MTT assays showed a significant increase in the survival of DRG cells after the addition of conditioned medium from hDPSCs and d-hDPSCs (Fig. 3B). Furthermore, compared with hDPSCs, a higher percentage of survival was observed in DRG cultures after the addition of conditioned medium from d-hDPSCs.

To detect the outgrowth of neurites in DRG cultures following $48 \mathrm{~h}$ of incubation with conditioned medium of hDPSCs and d-hDPSCs, immunocytochemical staining for $\beta$-III-tubulin was performed. A significant increase in the length of the longest neurite was observed after adding conditioned medium of hDPSCs and d-hDPSCs (Fig. 3C). In addition, conditioned medium of d-hDPSCs induced a distinct positive influence on neurite outgrowth compared to conditioned medium of undifferentiated hDPSCs. 

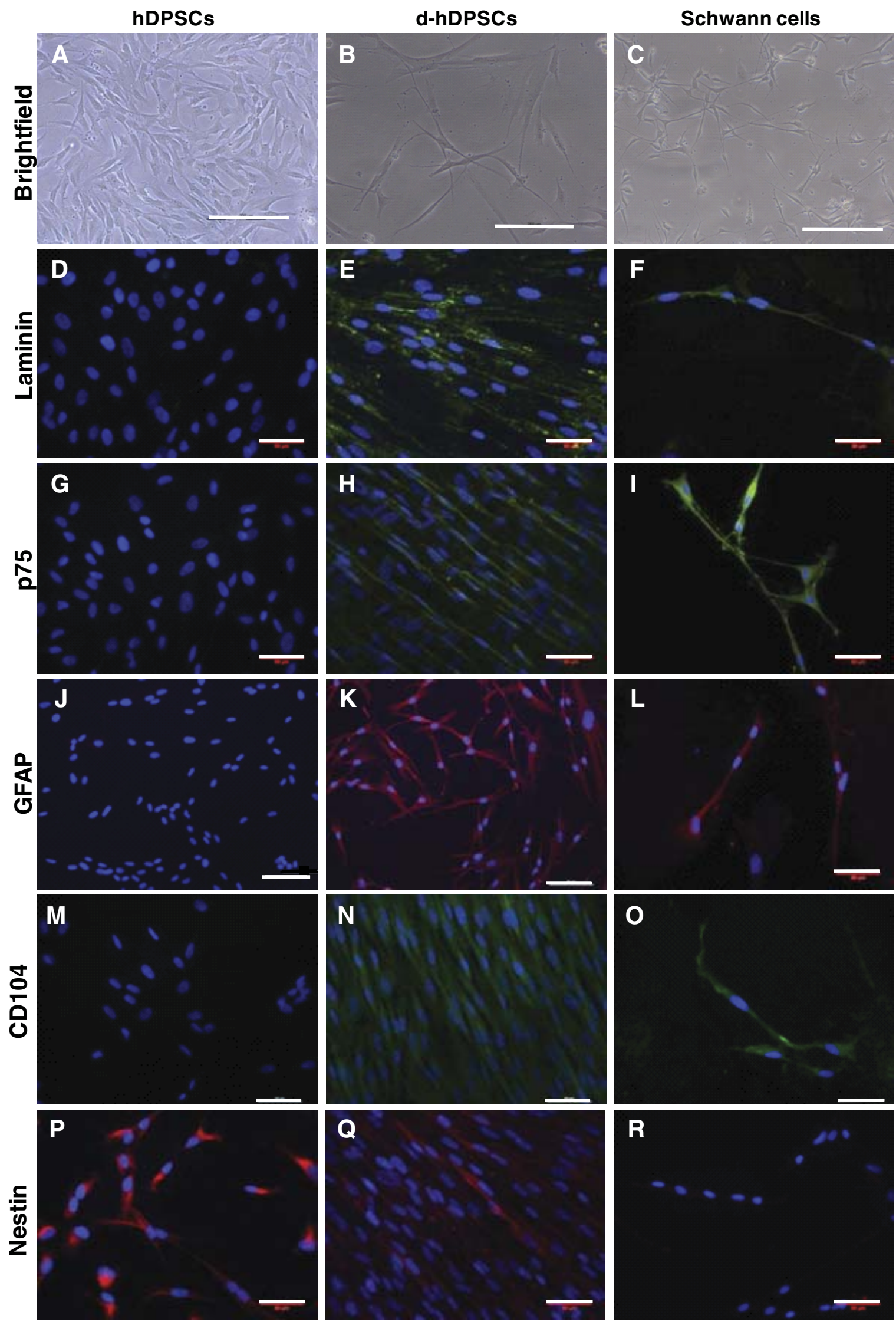

Figure 1. Phenotyping hDPSCs after Schwann cell differentiation. Brightfield imaging $(A-C)$ and immunocytochemistry $(D-R)$ were performed on hDPSCs $(A, D, G, J, M, P)$ and d-hDPSCs $(B, E, H, K, N, Q)$ for the typical Schwann cell markers laminin $(D-F)$, p75 $(G-I)$, GFAP $(J-L)$, CD104 $(M-O)$, and nestin $(P-R)$. Nuclei were counterstained with DAPI (blue). Primary rat Schwann cells $(C, F, I, L, O, R)$ were used as positive controls for differentiation. Scale bars $=200 \mu \mathrm{m}(A-C) ; 50 \mu \mathrm{m}(D-I, L-R) ; 100 \mu \mathrm{m}(J, K)$. 

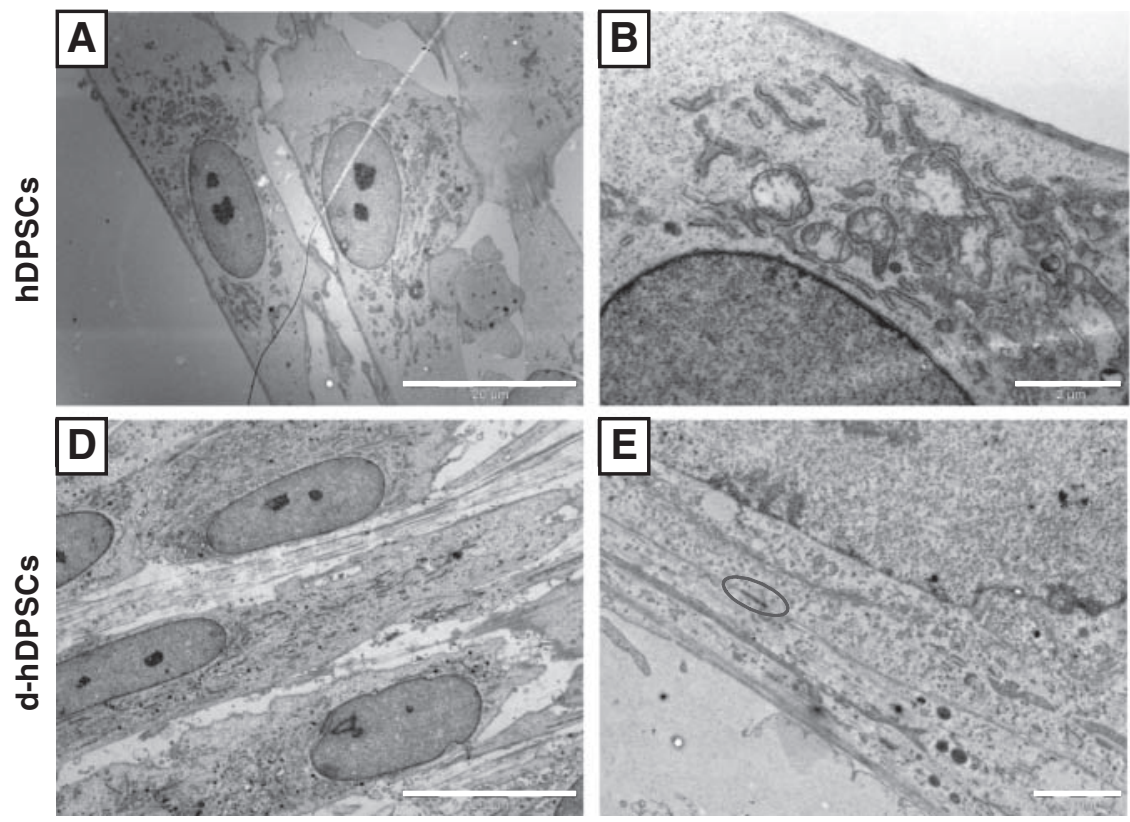

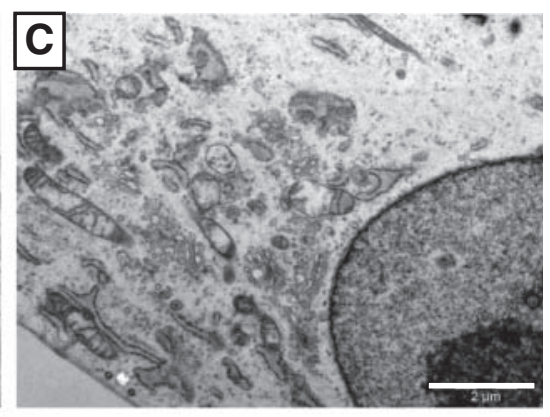

Figure 2. Transmission electron micrographs of hDPSCs $(A-C)$ and d-hDPSCs $(D, E)$. Ultrastructural characteristics of $\mathrm{d}$-hDPSCs differ markedly from those of hDPSCs, with cell-cell contacts ( $E$, oval) between neighboring cells. Scale bars $=$ $20 \mu \mathrm{m}(A, B, D) ; 2 \mu \mathrm{m}(C, E)$.

\section{d-hDPSCs are aligned in EngNT and guide neurite outgrowth in vitro}

The capacity of d-hDPSCs to contribute toward a beneficial neuroregenerative environment was assessed in vitro. After d-hDPSCs aligned within tethered collagen gels within $4-6 \mathrm{~h}$, constructs were stabilized by removal of interstitial fluid from the hydrogel. This process did not affect d-hDPSC survival (data not shown). Columns of aligned d-hDPSCs within the EngNT were visualized by means of immunofluorescence and confocal micros- copy (Fig. 4A). When dissociated DRG neurons were cultured on top of this aligned cellular material for $3 \mathrm{~d}$, neurite extension along aligned d-hDPSCs was observed (Fig. $4 B-C$ ). The relative frequency distribution of neurite deviation from the mean d-hDPSCs orientation revealed that the majority of neurites $(84 \pm 11 \%)$ deviated with an angle of only $0-30^{\circ}$ from the underlying d-hDPSC columns (Fig. $4 D$ ). Neurites growing near perpendicular $\left(80-90^{\circ}\right)$ to the overall direction of aligned d-hDPSCs were not observed.

A

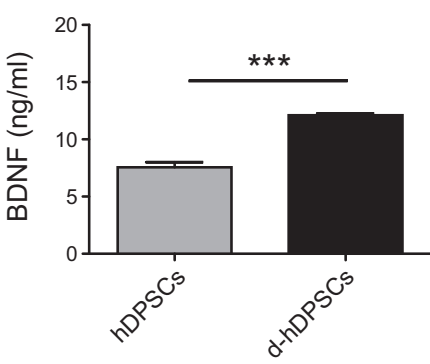

B

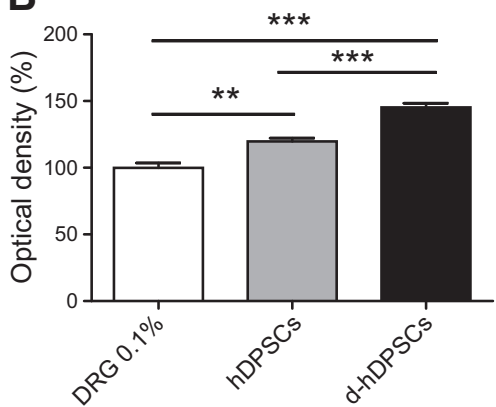

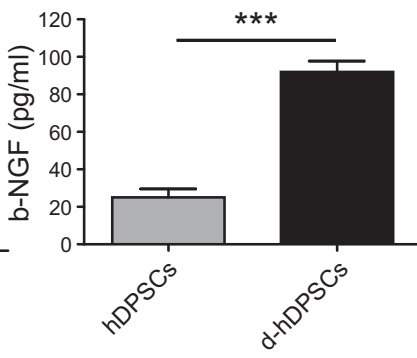

C

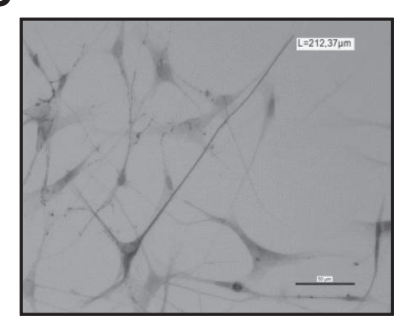

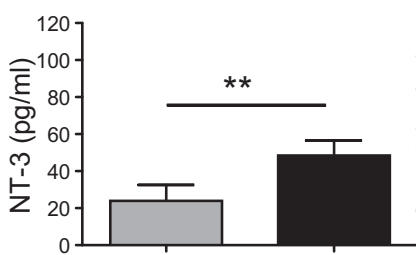
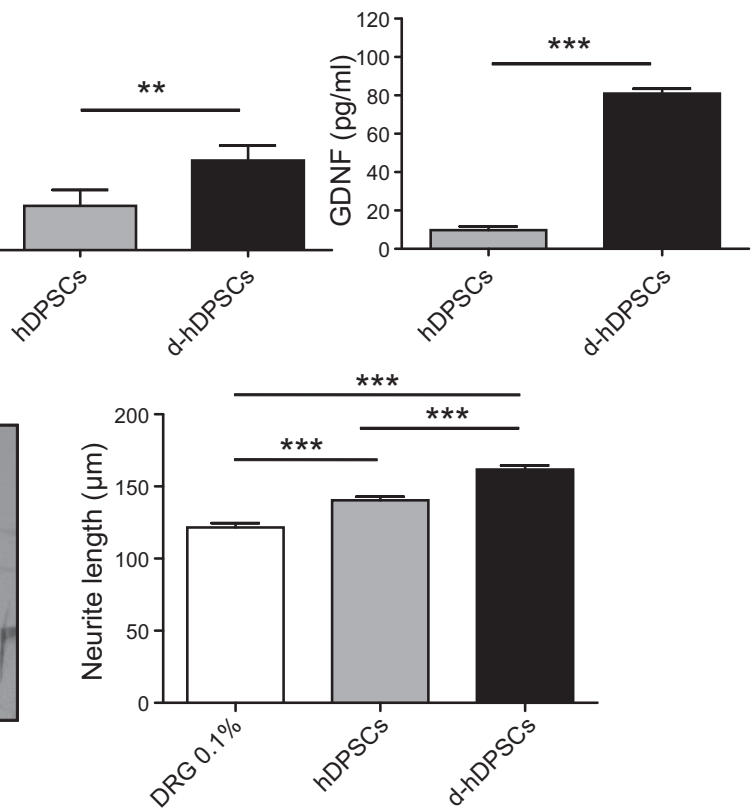

Figure 3. Neurotrophic factor secretion. A) ELISAs indicated a significant increase in BDNF, b-NGF, NT-3, and GDNF levels after differentiation $(n=9) . B, C)$ Neural survival $(B ; n=7)$ and neurite outgrowth $(C ; n=4)$ were significantly improved with conditioned medium from hDPSCs and d-hDPSCs, with the latter being more potent. Scale bar $=50 \mu \mathrm{m}$. Data represent means \pm SEM $* * P<0.01, * * * P<0.001$. 

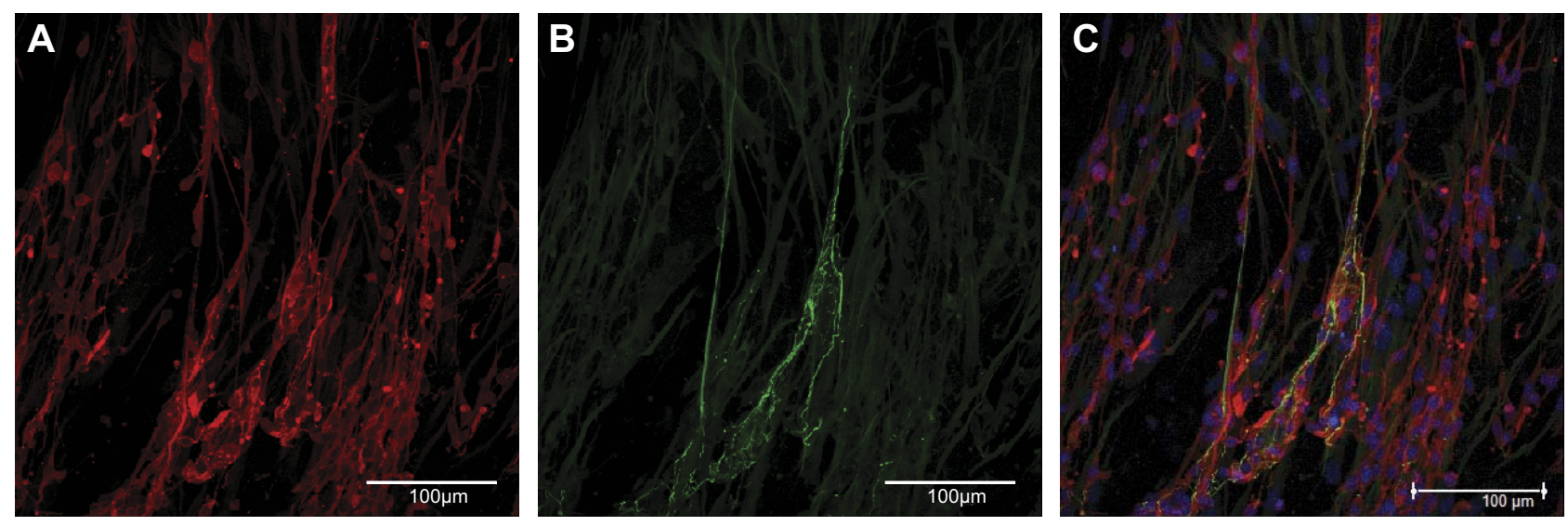

D

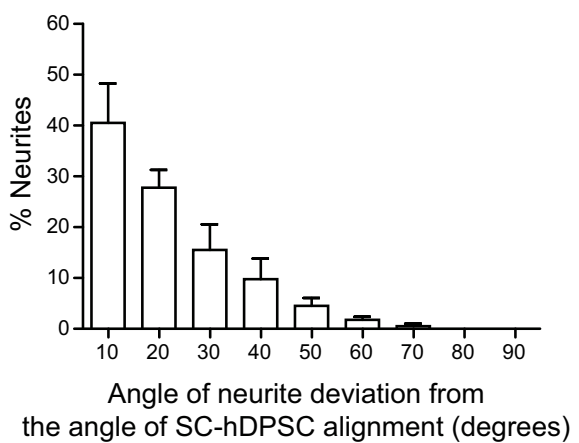

Figure 4. d-hDPSC alignment in EngNT guides neurite outgrowth in coculture. $A-C$ ) Confocal images represent d-hDPSCs (S100, red) and neurites (b-IIItubulin, green). Nuclei were counterstained with DAPI (blue). Scale bars $=100$ $\mu \mathrm{m} . D)$ Frequency distribution of neurite angles compared to mean angle of d-hDPSC alignment in each field (field volume: $9.8 \times 10^{6} \mu^{3}$ ). Data represent means $\pm \mathrm{SE}$ (in $10^{\circ}$ bins; $n=4$ ).

\section{Ultrastructural evaluation of myelination capacity of d-hDPSCs}

Three-dimensional cocultures of d-hDPSCs and DRGderived primary neurons in EngNT were established to assess the myelination capacity of d-hDPSCs. Cytoplasm of both cell types could be easily distinguished based on differential amounts of cell organelles. Neurites were characterized by numerous mitochondria, whereas dhDPSC cytoplasm was mainly occupied by rough endoplasmic reticulum and free ribosomes. Proximity of $\mathrm{d}$-hDPSCs and neurons resulted in an extensive number of cell-cell contacts (Fig. 5A). Neurites were engulfed by d-hDPSCs following enfoldment using pseudopodial processes. d-hDPSCs produced myelin sheaths ranging in thickness from 0.1 to $1 \mu \mathrm{m}$ (Fig. $5 B$ ). Once established, myelin sheaths contained multiple neurites and exhibited typical periodic and intraperiodic lines (Fig. 5C). Manual counting of the total number of d-hDPSCs and neurites showed that, on average, $20 \mathrm{~d}$-hDPSCs and 172 neurites $/ \mathrm{mm}^{2}$ hydrogel were present. The total number of neurites consisted of 4 subgroups: neurites that were in contact with d-hDPSCs $(14.26 \%)$, myelinated neurites $(6.42 \%)$, neurites that were ensheathed by the cytoplasm of d-hDPSCs $(16.40 \%)$, and the remaining fraction showing none of the previous characteristics $(62.93 \%)$ (Fig. 5D).

\section{DISGUSSION}

In the present study, we established a protocol for the differentiation of hDPSCs into cells with a Schwann cell phenotype and functionality in vitro. Although several researchers described the possible differentiation of bone marrow-derived MSCs or adipose-derived MSCs toward Schwann cells $(11,38,39)$, this is the first time, to our knowledge, that successful differentiation of hDPSC toward a Schwann cell phenotype has been established and well characterized. Following the differentiation protocol, hDPSCs expressed typical Schwann cell markers and promoted neuronal survival and neurite outgrowth. Moreover, in a 3D coculture model with neurons, d-hDPSCs guided neurite outgrowth and were able to myelinate neurites extended by DRG neurons.

Since DPSCs originate from migrating neural crest cells, they are thought to be predisposed toward differentiating into peripheral glial cells under the correct environmental conditions (16-19).

In addition to this neural crest lineage, the high proliferation capacity, multipotency, plasticity, and immunomodulatory properties of DPSCs make them excellent candidates for regenerative medicine purposes, especially in the field of neural tissue engineering (22, 27, 40, 41).

Differentiation of hDPSCs toward Schwann-like cells was induced in vitro by the addition of various factors: $\mathrm{BME}, \mathrm{RA}$, and growth media supplemented with a cocktail of growth factors containing PDGFaa, b-FGF, forskolin, and NRG. BME is known to promote the formation of neurite-like outgrowth $(42,43)$ as is seen in cell cultures after $24 \mathrm{~h}$ administration of BME. RA was used to further induce morphological cell changes, as several reports state that RA together with BME can work as a triggering factor that alters cell morphology. Furthermore, RA induces differentiation of embryonic 

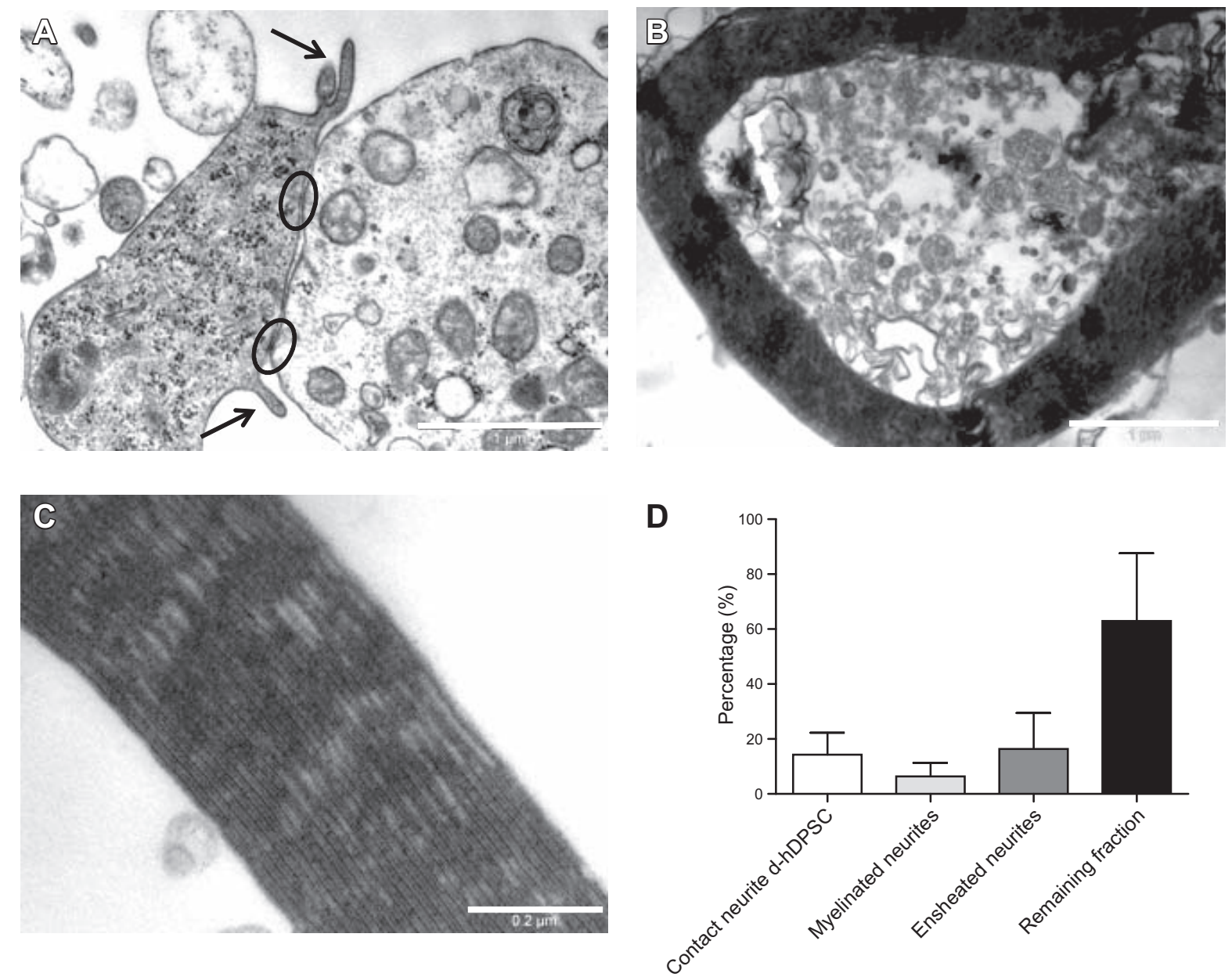

Figure 5. Ultrastructural analysis of myelination capacity of d-hDPSCs. A) Multiple cell-cell contacts (encircled) and enfoldment of neurites by pseudopodial processes of d-hDPSCs (arrows) were frequently observed. $B-C$ ) Myelin sheaths were present in the culture $(B)$, showing typical periodic and intraperiodic lines $(C)$. D) Total number of d-hDPSCs and neurites per square millimeter of hydrogel. Scale bars $=1 \mu \mathrm{m}(A, B) ; 0.2 \mu \mathrm{m}(C)$.

stem cells into neural cells and regulates the expression of transcription factors that play a role in neural cell determination $(30,44)$. An increase in cAMP, and thus an elevated expression of mitogenic genes, can be achieved when cells are treated with forskolin. Taken together, BME and RA have altered cell morphology, and further use of forskolin, b-FGF, PDGFaa, and NRG synergistically promote the differentiation of hDPSC into cells with Schwann cell characteristics.

The ultrastructural characteristics of undifferentiated hDPSCs have previously been described (29). As seen in our cultures, undifferentiated hDPSCs are fibroblast-like cells containing a perinuclear organelle-rich zone and a peripheral zone lacking any cell organelles. Furthermore no cell-cell contacts and extracellular matrix components were observed (29). After differentiation, we observed that d-hDPSCs adopted a spindle-shaped bipolar morphology with numerous organelles spread throughout the cell cytoplasm.

To confirm the Schwann cell-like phenotype of differentiated hDPSCs, the expression of multiple markers was evaluated. In order for MSCs to develop toward a neural cell lineage, nestin expression is essential (45). On differentiation, nestin expression is known to de- crease, which is in accordance with the lower levels of nestin seen in d-hDPSCs compared to undifferentiated hDPSCs. Whereas laminin, p75, GFAP, and CD104 expression was hardly detectable in undifferentiated hDPSCs, d-hDPSCs stained strongly positive for these glial markers, similar to Schwann cells. CD104, also known as integrin $\beta 4$, associates with integrin $\beta 6$ to form an adhesion receptor for laminins and is widely expressed by Schwann cells. These results demonstrate the successful morphological differentiation of hDPSCs toward Schwann-like cells.

Previous studies have demonstrated that DPSCs secrete an array of NFs both in vitro and in vivo and that different neuronal populations exhibit enhanced neuronal survival and neurite outgrowth in the presence of these DPSCs-derived NFs $(23-25,46)$. In line with these findings, we observed the secretion of GDNF, BDNF, NT-3, and b-NFG by undifferentiated hDPSCs and their beneficial effects on neuronal survival and neurite length of cultured dissociated DRG neurons. As denervated Schwann cells are known to secrete NFs, and axonal regeneration is reduced in the absence of Schwann cells (47), we predicted that d-hDPSCs would have better neuroprotective and neurotrophic effects 
than hDPSC. Indeed, not only did significantly more DRG neurons survive with the use of conditioned medium derived from d-hDPSC cultures compared to undifferentiated hDPSCs cultures; an increase in neurite length was also observed.

In the field of neural regeneration, different conduits (natural, synthetic, resorbable, and nonresorbable hydrogels or polymers), in all cases being hollow tubes, have been evaluated to provide guidance for regrowing axons (1). Although promising results are obtained, these conduits lack the microarchitecture typical of nerve tissue (48). For optimal nerve regeneration across a long gap, it is important to use a scaffold that mimics key features of the native environment: Schwann-like cells secreting neurotrophic factors (like denervated Schwann cells in an autograft), Schwann-like cells organized into aligned columns (like bands of Büngner), and Schwann-like cells surrounded by an aligned nanofibrillar collagen extracellular matrix (like the endoneurium).

Since our results showed that hDPSG were able to differentiate into Schwann-like cells and were capable of secreting NFs that play a role in neural regeneration, we evaluated whether d-hDPSCs were able to self-align in 3D collagen to form EngNT, and whether they could provide guidance for regrowing axons.

After seeding d-hDPSCs in a collagen type I hydrogel, alignment of $d$-hDPSCs was obtained, and this was stabilized using plastic compression to form EngNT, as previously shown using Schwann cells (8). This organization of aligned d-hDPSCs in a collagen matrix resembled the bands of Büngner, which are important for accurate guiding of axonal regeneration. Indeed, it has previously been shown that in the process of nerve regeneration, the organization of Schwann cells into columns (bands of Büngner) is of critical importance to guide and support axonal regeneration from the proximal to the distal end of the injury (48). Cells in a collagen gel will form stable integrin bonds with the collagen fibrils, and then cytoskeletal activity generates forces that contract the gel. EngNT formation as used here exploits this phenomenon; anchoring the ends of a rectangular cellular collagen gel results in development of a longitudinal axis of tension, causing cell elongation and alignment of cells and collagen fibers (8-10).

The majority of DRG neurites seeded on top of EngNT acquired the direction of aligned d-hDPSCs. In this manner, d-hDPSCs provided a strong guidance cue for neurite growth, which is necessary to promote neural regeneration in vivo. Our results were similar to previous studies where aligned glial cell environments supported and guided neurite growth in vitro (10, 49-51). The aligned cells rather than the collagen matrix are likely to be the main contributor to the promotion of neurite growth, since a previous study showed that little outgrowth was detected in decellularized and acellular constructs compared to EngNT containing live Schwann cells (10).

Tethered hydrogels were used to establish 3D cocultures of DRG neurons and d-hDPSCs to investigate the myelination capacity of the latter. Although the majority of neurites were not myelinated, a close apposition between cellular extensions of d-hDPSCs and neurons was frequently observed. Often these areas were char- acterized by the presence of multiple cell junctions, which, in turn, might represent the initiating step of the myelination process (52). The in vitro model used here showed that when neurons and d-hDPSCs were cultured together within a 3D hydrogel environment, the d-hDPSCs spontaneously ensheathed neurites and, in some cases, generated myelin structures, both characteristics that would be associated with neuronSchwann cell interactions in vivo.

In the present study, hDPSCs were successfully differentiated toward Schwann-like cells both on the morphological and functional level. d-hDPSCs expressed characteristic Schwann cell markers, promoted neurite outgrowth in 2D and 3D culture environments, and exhibited typical Schwann cell interactions with neurons, such as ensheathment and myelination of neurites. These features, coupled with their potential clinical availability and utility as a component of tissue engineered constructs, make hDPSCs promising candidates for investigation as cell-based therapies in peripheral nerve injury.

The authors are grateful to Dr. Constantinus Politis and Dr. Luc Vrielinck (Ziekenhuis Oost Limburg, Genk Diepenbeek, Belgium) for providing dental pulp tissue and to Marc Jans for excellent tissue processing for transmission electron microscopy. This research was supported by multiple grants to W.M. and K.S. K.S. acknowledges funding from Hasselt University (05G02BOF), a travel grant from Research Foundation Flanders [Fonds Wetenschappelijk Onderzoek (FWO), grant K200713N] and funding by the Interreg Euregio Meuse-Rhine IV-A consortium BioMIMedics. W.M. benefits from a grant via FWO (GO29112FWO) and via the Boehringer Ingelheim Fonds.

\section{REFERENCES}

1. Deumens, R., Bozkurt, A., Meek, M. F., Marcus, M. A., Joosten, E. A., Weis, J., and Brook, G. A. (2010) Repairing injured peripheral nerves: bridging the gap. Progr. Neurobiol. 92, 245-276

2. Hall, S. M. (1986) The effect of inhibiting Schwann cell mitosis on the re-innervation of acellular autografts in the peripheral nervous system of the mouse. Neuropathol. Appl. Neurobiol. 12, 401-414

3. Ichihara, S., Inada, Y., and Nakamura, T. (2008) Artificial nerve tubes and their application for repair of peripheral nerve injury: an update of current concepts. Injury 39(Suppl. 4), 29-39

4. Bell, J. H., and Haycock, J. W. (2012) Next generation nerve guides: materials, fabrication, growth factors, and cell delivery. Tissue Eng. B Rev. 18, 116-128

5. Gu, X., Ding, F., Yang, Y., and Liu, J. (2011) Construction of tissue engineered nerve grafts and their application in peripheral nerve regeneration. Progr. Neurobiol. 93, 204-230

6. Nectow, A. R., Marra, K. G., and Kaplan, D. L. (2012) Biomaterials for the development of peripheral nerve guidance conduits. Tissue Eng. B Rev. 18, 40-50

7. Aurand, E. R., Lampe, K. J., and Bjugstad, K. B. (2012) Defining and designing polymers and hydrogels for neural tissue engineering. Neurosci. Res. 72, 199-213

8. Geckil, H., Xu, F., Zhang, X., Moon, S., and Demirci, U. (2010) Engineering hydrogels as extracellular matrix mimics. Nanomedicine 5, 469-484

9. Brown, R. A., and Phillips, J. B. (2007) Cell responses to biomimetic protein scaffolds used in tissue repair and engineering. Int. Rev. Cytol. 262, 75-150

10. Georgiou, M., Bunting, S. C., Davies, H. A., Loughlin, A. J., Golding, J. P., and Phillips, J. B. (2013) Engineered neural tissue for peripheral nerve repair. Biomaterials 34, 7335-7343 
11. Ren, Z., Wang, Y., Peng, J., Zhao, Q., and Lu, S. (2012) Role of stem cells in the regeneration and repair of peripheral nerves. Rev. Neurosci. 23, 135-143

12. Terenghi, G., Wiberg, M., and Kingham, P. J. (2009) Chapter 21: use of stem cells for improving nerve regeneration. Int. Rev. Neurobiol. 87, 393-403

13. Javazon, E. H., Beggs, K. J., and Flake, A. W. (2004) Mesenchymal stem cells: paradoxes of passaging. Exp. Hematol. 32, 414-425

14. Ross, J. J., and Verfaillie, C. M. (2008) Evaluation of neural plasticity in adult stem cells. Phil. Trans. R. Soc. Lond. 363, 199-205

15. Gronthos, S., Mankani, M., Brahim, J., Robey, P. G., and Shi, S. (2000) Postnatal human dental pulp stem cells (DPSCs) in vitro and in vivo. Proc. Natl. Acad. Sci. U. S. A. 97, 13625-13630

16. Chai, Y., Jiang, X., Ito, Y., Bringas, P., Jr., Han, J., Rowitch, D. H., Soriano, P., McMahon, A. P., and Sucov, H. M. (2000) Fate of the mammalian cranial neural crest during tooth and mandibular morphogenesis. Development 127, 1671-1679

17. Graham, A., Begbie, J., and McGonnell, I. (2004) Significance of the cranial neural crest. Dev. Dyn. 229, 5-13

18. Miletich, I., and Sharpe, P. T. (2004) Neural crest contribution to mammalian tooth formation. Birth Defects Res. C Embryo Today 72, 200-212

19. Thesleff, I., and Aberg, T. (1999) Molecular regulation of tooth development. Bone 25, 123-125

20. Papaccio, G., Graziano, A., d'Aquino, R., Graziano, M. F., Pirozzi, G., Menditti, D., De Rosa, A., Carinci, F., and Laino, G. (2006) Long-term cryopreservation of dental pulp stem cells (SBP-DPSCs) and their differentiated osteoblasts: a cell source for tissue repair. J. Cell. Physiol. 208, 319-325

21. Huang, A. H., Snyder, B. R., Cheng, P. H., and Chan, A. W (2008) Putative dental pulp-derived stem/stromal cells promote proliferation and differentiation of endogenous neural cells in the hippocampus of mice. Stem Cells 26, 2654-2663

22. Martens, W., Bronckaers, A., Politis, C., Jacobs, R., and Lambrichts, I. (2013) Dental stem cells and their promising role in neural regeneration: an update. Clin. Oral Invest. 17, 1969-1983

23. Nosrat, I. V., Smith, C. A., Mullally, P., Olson, L., and Nosrat, C. A. (2004) Dental pulp cells provide neurotrophic support for dopaminergic neurons and differentiate into neurons in vitro; implications for tissue engineering and repair in the nervous system. Eur. J. Neurosci. 19, 2388-2398

24. Nosrat, I. V., Widenfalk, J., Olson, L., and Nosrat, C. A. (2001) Dental pulp cells produce neurotrophic factors, interact with trigeminal neurons in vitro, and rescue motoneurons after spinal cord injury. Dev. Biol. 238, 120-132

25. Arthur, A., Shi, S., Zannettino, A. C., Fujii, N., Gronthos, S., and Koblar, S. A. (2009) Implanted adult human dental pulp stem cells induce endogenous axon guidance. Stem Cells 27, 22292237

26. Arthur, A., Rychkov, G., Shi, S., Koblar, S. A., and Gronthos, S. (2008) Adult human dental pulp stem cells differentiate toward functionally active neurons under appropriate environmental cues. Stem Cells 26, 1787-1795

27. Gronthos, S., Brahim, J., Li, W., Fisher, L. W., Cherman, N., Boyde, A., DenBesten, P., Robey, P. G., and Shi, S. (2002) Stem cell properties of human dental pulp stem cells. J. Dental Res. 81, 531-535

28. Kiraly, M., Porcsalmy, B., Pataki, A., Kadar, K., Jelitai, M., Molnar, B., Hermann, P., Gera, I., Grimm, W. D., Ganss, B., Zsembery, A., and Varga, G. (2009) Simultaneous PKC and cAMP activation induces differentiation of human dental pulp stem cells into functionally active neurons. Neurochem. Int. 55, 323-332

29. Struys, T., Moreels, M., Martens, W., Donders, R., Wolfs, E., and Lambrichts, I. (2011) Ultrastructural and immunocytochemical analysis of multilineage differentiated human dental pulp- and umbilical cord-derived mesenchymal stem cells. Cells Tissues Organs 193, 366-378

30. Dezawa, M., Takahashi, I., Esaki, M., Takano, M., and Sawada, H. (2001) Sciatic nerve regeneration in rats induced by transplantation of in vitro differentiated bone-marrow stromal cells. Eur. J. Neurosci. 14, 1771-1776

31. Wei, Y., Zhou, J., Zheng, Z., Wang, A., Ao, Q., Gong, Y., and Zhang, X. (2009) An improved method for isolating Schwann cells from postnatal rat sciatic nerves. Cell Tissue Res. 337, 361-369

32. Bretschneider, A., Burns, W., and Morrison, A. (1981) "Pop-off" technic. The ultrastructure of paraffin-embedded sections. Am. J. Clin. Pathol. 76, 450-453
33. Phillips, J. B., and Brown, R. A. (2004) Self-aligning tissue growth guide. International Patent WO2004087231

34. Brown, R. A., Wiseman, M., Chuo, C. B., Cheema, U., and Nazhat, S. N. (2005) Ultrarapid engineering of biomimetic materials and tissues: fabrication of nano- and microstructures by plastic compression. Adv. Func. Mater. 15, 1762-1770

35. Phillips, J. B., and Brown, R. (2011) Micro-structured materials and mechanical cues in 3D collagen gels. Methods Mol. Biol. 695, 183-196

36. East, E., Golding, J. P., and Phillips, J. B. (2009) A versatile 3D culture model facilitates monitoring of astrocytes undergoing reactive gliosis. J. Tissue Eng. Regen. Med. 3, 634-646

37. Wright, K. E., Liniker, E., Loizidou, M., Moore, C., Macrobert, A. J., and Phillips, J. B. (2009) Peripheral neural cell sensitivity to mTHPC-mediated photodynamic therapy in a $3 \mathrm{D}$ in vitro model. Br. J. Cancer 101, 658-665

38. Kingham, P. J., Kalbermatten, D. F., Mahay, D., Armstrong, S. J., Wiberg, M., and Terenghi, G. (2007) Adipose-derived stem cells differentiate into a Schwann cell phenotype and promote neurite outgrowth in vitro. Exp. Neurol. 207, 267-274

39. Mantovani, C., Terenghi, G., and Shawcross, S. G. (2012) Isolation of adult stem cells and their differentiation to Schwann cells. Methods Mol. Biol. 916, 47-57

40. Ibarretxe, G., Crende, O., Aurrekoetxea, M., Garcia-Murga, V., Etxaniz, J., and Unda, F. (2012) Neural crest stem cells from dental tissues: a new hope for dental and neural regeneration. Stem Cells Int. 2012, 103503

41. Pierdomenico, L., Bonsi, L., Calvitti, M., Rondelli, D., Arpinati, M., Chirumbolo, G., Becchetti, E., Marchionni, C., Alviano, F., Fossati, V., Staffolani, N., Franchina, M., Grossi, A., and Bagnara, G. P. (2005) Multipotent mesenchymal stem cells with immunosuppressive activity can be easily isolated from dental pulp. Transplantation 80, 836-842

42. Deng, W., Obrocka, M., Fischer, I., and Prockop, D. J. (2001) In vitro differentiation of human marrow stromal cells into early progenitors of neural cells by conditions that increase intracellular cyclic AMP. Biochem. Biophys. Res. Commun. 282, 148-152

43. Woodbury, D., Schwarz, E. J., Prockop, D. J., and Black, I. B. (2000) Adult rat and human bone marrow stromal cells differentiate into neurons. J. Neurosci. Res. 61, 364-370

44. Fraichard, A., Chassande, O., Bilbaut, G., Dehay, C., Savatier, P., and Samarut, J. (1995) In vitro differentiation of embryonic stem cells into glial cells and functional neurons. J. Cell Sci. 108(Pt. 10), 3181-3188

45. Gage, F. H., Coates, P. W., Palmer, T. D., Kuhn, H. G., Fisher, L. J., Suhonen, J. O., Peterson, D. A., Suhr, S. T., and Ray, J. (1995) Survival and differentiation of adult neuronal progenitor cells transplanted to the adult brain. Proc. Natl. Acad. Sci. U. S. A. 92, 11879-11883

46. Sakai, K., Yamamoto, A., Matsubara, K., Nakamura, S., Naruse, M., Yamagata, M., Sakamoto, K., Tauchi, R., Wakao, N., Imagama, S., Hibi, H., Kadomatsu, K., Ishiguro, N., and Ueda, M. (2012) Human dental pulp-derived stem cells promote locomotor recovery after complete transection of the rat spinal cord by multiple neuroregenerative mechanisms. J. Clin. Invest. 122, 80-90

47. Frostick, S. P., Yin, Q., and Kemp, G. J. (1998) Schwann cells, neurotrophic factors, and peripheral nerve regeneration. Microsurgery 18, 397-405

48. Ribeiro-Resende, V. T., Koenig, B., Nichterwitz, S., Oberhoffner, S., and Schlosshauer, B. (2009) Strategies for inducing the formation of bands of Bungner in peripheral nerve regeneration. Biomaterials 30, 5251-5259

49. East, E., de Oliveira, D. B., Golding, J. P., and Phillips, J. B. (2010) Alignment of astrocytes increases neuronal growth in three-dimensional collagen gels and is maintained following plastic compression to form a spinal cord repair conduit. Tissue Eng. 16, 3173-3184

50. Lietz, M., Dreesmann, L., Hoss, M., Oberhoffner, S., and Schlosshauer, B. (2006) Neuro tissue engineering of glial nerve guides and the impact of different cell types. Biomaterials 27, 1425-1436

51. Phillips, J. B., Bunting, S. C., Hall, S. M., and Brown, R. A. (2005) Neural tissue engineering: a self-organizing collagen guidance conduit. Tissue Eng. 11, 1611-1617

52. Sherman, D. L., and Brophy, P. J. (2005) Mechanisms of axon ensheathment and myelin growth. Nat. Rev. Neurosci. 6, 683-690

Received for publication October 15, 2013. Accepted for publication December 9, 2013. 